\title{
ESTUDO DAS IMUNOGLOBULINAS EM 5 CASOS DE DISTROFIA MIOTÔNICA
}

\author{
Charles P. Tilbery * \\ ABRAM TOPCZEWSKI * \\ WILSON L. SANVITo ** \\ Augusta TAKeDA*** \\ Matilde RASKIN ***
}

A distrofia miotônica é moléstia heredofamiliar caracterizada clinicamente por fácies miopática, fraqueza muscular generalizada com predominio distal, miotonias generalizadas, alopécia frontal, catarata, atrofia gonadal, diminuição do metabolismo basal e déficit intelectual ${ }^{1,8}$.

O metabolismo das proteínas plasmáticas, principalmente as imunoglobulinas, tem sido ultimamente estudado em moléstias neurológicas, procurando-se provável etiologia autoimune. Particularmente, na distrofia miotônica tem sido assinalada redução dos niveis de imunoglobulina $G$, provàvelmente devido a aumento de seu catabolismo ${ }^{3,9,10,11}$.

\section{MATERIAL E METODOS}

Nossa casuistica consta de 5 pacientes com distrofia miotonica, sendo o diagróstico baseado em critérios clinicos e histopatológicos (Quadro 1). Em todos os casos foi feita a dosagem de proteinas totais pelo método do biureto ${ }^{4}$, o proteinograma em acetato de celulose ', a imunoeletroforerese em ágar de acordo com a técnica de Grabar e Burtin ${ }^{2}$ e a imunodifusão quantitativa pela técnica de Mancini e col. ${ }^{5}$.

\section{COMENTAR IOS}

Zinneman e Rotstein ${ }^{11}$ estudaram as proteínas plasmáticas em 12 pacientes com distrofia miotônica, descrevendo, em 7 deles, níveis anormalmente baixos de gamaglobulinas. Observaram estes autores que, após imunizações com vacinas, os niveis de gamaglobulina retornavam à normalidade. Estes dados sugerem que pacientes com distrofia miotônica tendem a apresentar níveis baixos de gamaglobulina em seu soro, embora este fenômeno não seja evidente durante toda a evoluçāo da moléstia. É provável que a

Trabalho da Disciplina de Neurologia do Departamento de Clínica Médica da Faculdade de Ciências Médicas da Santa Casa de São Paulo e da Secção Médica do Instituto Adolfo Lutz de São Paulo: * Médicos residentes; * Professor associado; *** Biologistas. 
estimulação antigênica, durante periodo de imunização, seja responsável pelos niveis normais de gamaglobulina em determinadas fases da moléstia (infecções adquiridas ou vacinações).

Referem ainda Zinneman e Rotstein ${ }^{11}$ niveis altos de betaglobulina em todos os seus pacientes e ausência de relação entre a gravidade do quadro clinico e o grau de alterações nas proteinas. Oppenheimer e Milhorat ${ }^{6}$ não encontraram niveis altos de betaglobulina.

As proteínas plasmáticas dotadas de atividade imunológica são denominadas imunoglobulinas e classificadas em três grupos principais: imunoglobulina G (IgG), imunoglobulina A (IgA) e imunoglobulina M (IgM). Wochner e col. ${ }^{10}$ encontraram diminuição da IgG em 19 pacientes com distrofia miotônica, com ausência de alterações da IgM e da IgA, num estudo comparativo com 11 pacientes com outras doenças neuromusculares. Acreditam estes autores que a diminuição da IgG, na distrofia miotônica, seja devida à aceleração do catabolismo desta imunoglobulina. Recentemente, Jensen e col. ${ }^{3}$ comprovaram estes dados em 4 pacientes de um grupo de 8 , em que houve queda acentuada de IgG.

\begin{tabular}{lcccc}
\hline Nome & Registro & Idade & Cor & Sexo \\
\hline \hline Caso 1 (A.C.) & 516.036 & 35 & $\mathrm{~b}$ & $\mathrm{~m}$ \\
Caso 2 (M.C.) & 402.383 & 44 & $\mathrm{~b}$ & $\mathrm{f}$ \\
Caso 3 (A.H.C.) & 446.175 & 24 & $\mathrm{~b}$ & $\mathrm{~m}$ \\
Caso 4 (A.S.) & 322.685 & 33 & $\mathrm{~b}$ & $\mathrm{f}$ \\
Caso 5 (A.N.) & 790.624 & 30 & $\mathrm{~b}$ & $\mathrm{f}$ \\
\hline
\end{tabular}

Quadro 1 - Identificação dos 5 casos de distrofia miotônica estudados.

\begin{tabular}{|c|c|c|c|c|c|c|c|}
\hline \multirow{3}{*}{$\begin{array}{l}\text { Casos } \\
\text { Valores } \\
\text { normais }\end{array}$} & \multirow{3}{*}{$\begin{array}{l}\begin{array}{l}\text { Proteínas } \\
\text { totais }\end{array} \\
6,4-8 \mathrm{mg} \%\end{array}$} & \multicolumn{6}{|c|}{ Eletroforese } \\
\hline & & & $\cdots$. & $\cdots-\cdots$ & - & -- & $\cdots$ \\
\hline & & $\begin{array}{c}\text { Pré-albumina } \\
0,03-0,25\end{array}$ & $\begin{array}{r}\text { Albumina } \\
\mathbf{3}, 80-\mathbf{5}, 50\end{array}$ & $\begin{array}{l}\text { Alfa-1* } \\
0,10-0,25\end{array}$ & $\begin{array}{l}\text { Alfa-2 * } \\
0,30-0,65\end{array}$ & $\begin{array}{c}\text { Beta * } \\
0,45-0,90\end{array}$ & $\underset{0,80-1,60}{\text { Gama * }}$ \\
\hline 1 & 6,5 & 0,60 & 4,02 & 0,15 & 0,45 & 0,54 & 0,78 \\
\hline 2 & 7,9 & 0,08 & 5,37 & 0,16 & 0,63 & 0,87 & 0,79 \\
\hline 3 & 7,4 & 0,04 & 5,06 & 0,15 & 0,37 & 0,49 & 1,39 \\
\hline 4 & 5,9 & 0,06 & 3,48 & 0,12 & 0,47 & 0,71 & 1,06 \\
\hline 5 & 8,1 & 0,08 & 4,70 & 0,24 & 0,81 & 0,89 & 1,39 \\
\hline
\end{tabular}


Em nossos casos a dosagem de proteinas totais do soro sangüineo revelou riscreta diminuição no caso 4 (Quadro 2). Mediante eletroforese em acetato de celulose observamos aumento da pré-albumina no caso 1 , aumento da globulina alfa 2 no caso 5, diminuição de albumina no caso 4 e diminuição de albumina no caso 4 e diminuição de gamaglobulina nos casos 1 e 2 (Quadro 2).

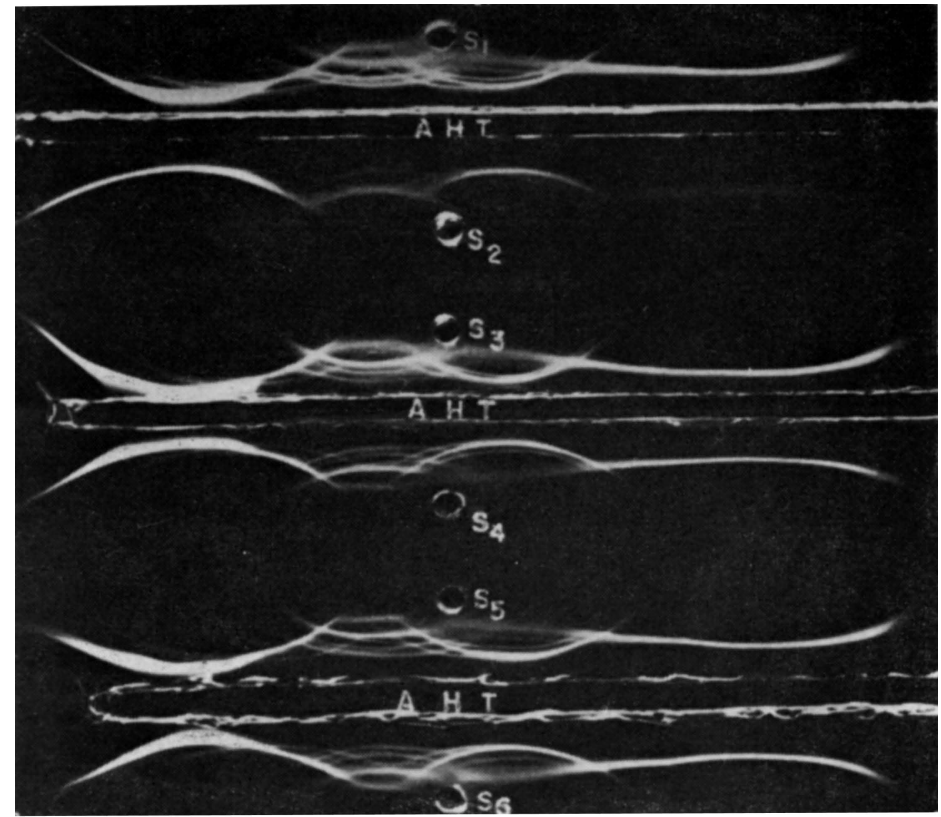

Fig. 1 - Imunoetetroforese dos soros dos pacientes S1, S2, S3, S4 $e$ $\mathrm{S} 5$, sendo que S6 é o soro normal com controle nas canaletas contendo o soro de corneiro anti-humano.

A análise imunoeletroforética dos soros sangüíneos revelou diminuição bem evidente da imunoglobulina $G$ nos casos 1 e 2, comparando-se as linhas de precipitação nestes dois casos com as do soro normal (S6 na Fig. 1). Nota-se, ainda, acentuação da linha da imunoglobulina $M$ nos casos 1, 2, 4 e 5, quando comparada com a normal.

Os dados da imunodifusão quantitativa (Fig. 2 e Quadro 3) mostram haver diminuição da imunoglobulina $G$, através do alo, nos casos 1 e 2, quando comparados com os padrões de 300, 1000 e $2000 \mathrm{mg} \%$. Analisando o alo correspondente à imunoglobulina $\mathrm{A}$ não notamos alterações, frente aos padrões de 62, 215 e $440 \mathrm{mg} \%$. Houve discreto aumento da imunoglobulina $M$ nos casos 1,4 e 5 e aumento considerável no caso 2 , em relação ao padrão de 22,64 e $140 \mathrm{mg} \%$, confirmando os cados obtidos na imunoeletroforese. 


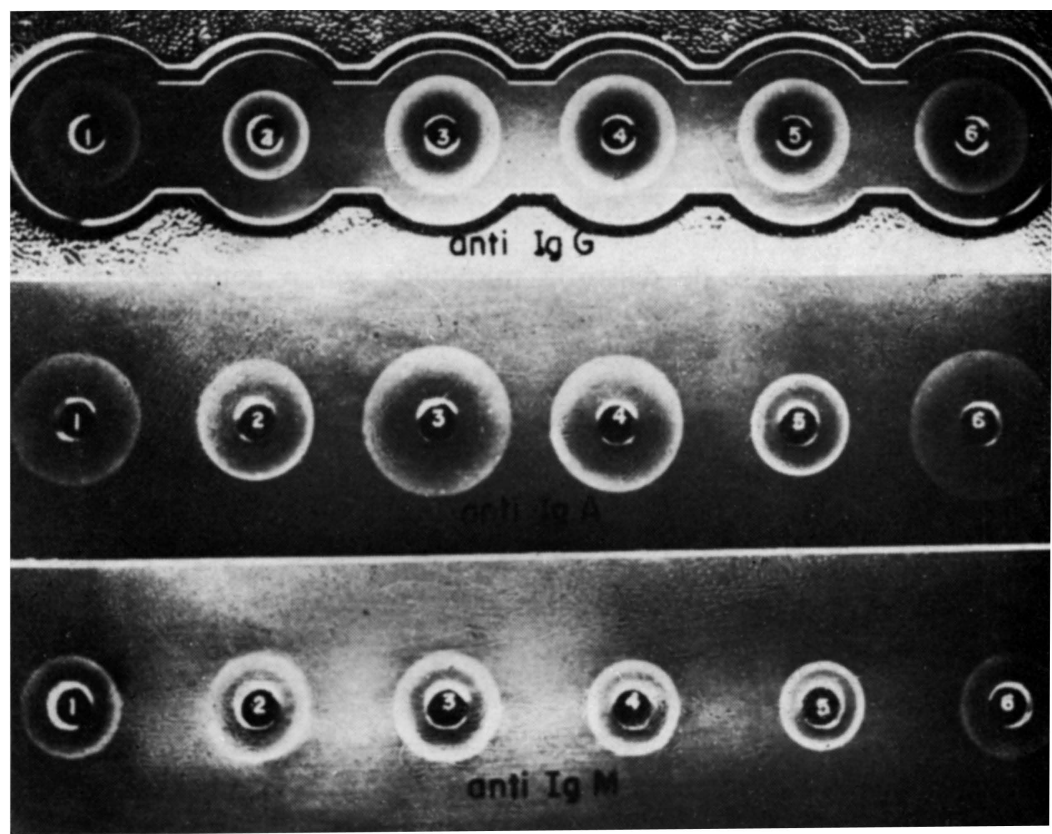

Fiq. 2 - Imunodifusão quantitativa dos soros dos casos 1, 2, 3, 4, 5 respectivamente, sendo 6 de soro normal. A primeira linha da placa impregnada com anti-IgG humano, a segunda linha da placa impregnada com anti-IgA hu. mano e a terceira linha da placa impregnada com anti-IgM humano.

\begin{tabular}{cccc}
\hline & \multicolumn{2}{c}{ IgA } & \multicolumn{2}{c}{ IgG } & IgM \\
Casos & Valor normal: & Valor normal: & Valor normal: \\
& $288 \pm 121 \mathrm{mg} \%$ & $1240 \pm 270 \mathrm{mg} \%$ & $80 \pm 29 \mathrm{mg} \%$ \\
\hline 1 & 310 & 720 & 128 \\
2 & 310 & 530 & 280 \\
3 & 215 & 1320 & 64 \\
4 & 188 & 1600 & 128 \\
\hline
\end{tabular}

Qualro 3 - Dados obtidos na imunodifusio quantitativa.

Nossos resultados concordam com àqueles obtidos por Zinneman e Rotstein ${ }^{11}$, por Wochner e col. ${ }^{10}$ e por Jensen e col. ${ }^{3}$, no que tange às gamaglobulinas (IgG e IgA). Em relação à betaglobulina, nossos resultados concordam com os obtidos por Oppenheimer e Milhorat ${ }^{6}$, que referem não haver alteração desta fração globulinica na distrofia miotônica.

Em nossos casos não observamos relação entre a gravidade da moléstia e as alteraçōes imunoeletroforéticas, como já foi salientado na literatura ${ }^{11}$. 
Os níveis elevados de IgM poderiam ser explicados por estimulação antigênica, uma vez que Wochner e col. ${ }^{10}$ salientam que, na distrofia miotônica, a aceleração do catabolismo de imunoglobulinas atingiria somente a cadeia pesada da IgG.

R E U M O

São estudados 5 casos de distrofia miotônica sob o ponto de vista imunoeletroforético. Os resultados obtidos mostram queda acentuada da imunoglobulina G (IgG) em dois casos.

\section{S U M M A R Y}

Immunoelectrophoretic study in five cases of myotomic dystrophy

The cases of five patients with myotonic dystrophy studied by immunoeletrophoretic analysis are reported. The decrease of imunoglobulin $G$ (IgG) in two cases is stressed.

\section{REFEREN CIAS}

1. B!.THLEM, J. - Muscle Pathology. North-Holland Publishing Co., AmsterdamLondon, 1970.

2. CRABAR, P. \& BURTIN, P. -- Immuno-eletrophoretic Analysis. Elsevier Puslishing Co., Amsterdam-London-New York, 1964.

3. JENSEN, H.; JENSEN, K. B. \& JARNUM, S. - Turnover of IgG and IgM in myotonic aystrophy. Neurology (Minneapolis) 21:68, 1971.

4. KABAT, E. A. \& MAYER, M. M. - Experimental Immuno-chemistry. Charles C. Thomas, Springfield (Illinois), 1961.

5. MANCINI, G.; CARBONARA, A. O. \& HERMANS, J. F. - Immunochemical quantitation of antigens by single radial immunodiffusion. Immunochemistry $2: 235,1965$.

6. OPPENHEIMER, H. \& MILHORAT A. T. - Serum proteins, lipoproteins and glicoproteins in muscular dystrophy and related diseases. Ann. New York Acad. Sci. 94:308, 1961.

7. PAGET, M. - Microelectrophorèse des proteines du sérum sur acetate de cellulose gelatineaux. Ann. Biol. Clin. 23:209, 1965.

8. SILVA, J. B. \& BARBIERI, T. A. - Distrofia miotônica: análise clínicogenetıca de uma familia. Arq. Neuro-Psiçuiat. (São Paulo) 28:65, 1970.

9. WATTERS, G. V. \& WILliams, T. W. - Early onset of myotonic dystrophy: clinical and laboratory findings in five families and a review of the literature. Arch. Neurol. (Chicago) 17:137, 1967.

10. WOCHNER, R. D.; GENEVIEVE, D.; STROBER, W. \& WALDMANN, T. A. Accelerated breakdown of immunoglobulin G (IgG) in myotonic dystrophy: a hereditary error of immunoglobulin catabolism. J. Clin. Invest. 45:321, 1966.

11. ZINNEMAN, H. H. \& ROTSTEIN, J. - A study of gamaglobulins in dystrophia myotonica. J. Lab. Clin. Med. 47:907, 1956.

Departamento de Medicina - Disciplina de Neurologia - Faculdade de Ciências Médicas da Santa Casa de São Paulo - Rua Cesário Motta Júnior 112 - 01221 São Paulo, SP - Brasil. 